\title{
Emerging frontiers in Entrepreneurship through Retail-E-Business: 'Centripetal momentum' engaged Product Life Cycle model
}

\author{
Salil K. Sen \\ Viput Ongsakul
}

NIDA Business School, Bangkok, Thailand

\begin{abstract}
Key Words
E-business to e-development, sustaining entrepreneurship, centripetal momentum, product life cycle, Thailand 4.0, resilience to cyber threats such as ransomware
\end{abstract}

\begin{abstract}
Cyber-space is a milieu of challenges and opportunities. The proliferation of popular e-portals along with looming ransomware creates the research challenge for this paper. E-based transactions are pervading at all levels of our connected society and needs to be self-sustaining. Given the inherent complexity of e-business models and virtual transaction systems, this paper aims to address the linkage between the product / service offerings in the e-business domain with stages of the product / service life cycle model. The paper addresses the threat gap evoked by vulnerability of cyber security issues such as ransomware, enforcing 'back to the future' for reliable pathways for cyber security (Lawerence, et. al. 2017). The purpose of this conceptually grounded work is to assess the diffusion of innovation at introduction, nascency, growth and maturity stages of the product / service life cycle. Diffusion of innovation product - service life cycle literature informs this research and attempts to analyze the lifecycle stage transition using concepts on centripetal momentum.

The Framework Method structures the methodology of this paper, that analyses qualitative data for thematic analysis or qualitative content analysis (Gale, Heath, Cameron, Rashid and Redwood, 2013). There are a number of findings such as (i) the rate of diffusion of innovation and its effect on sustainability, (ii) impact on entrepreneurship to self-sustaining e-business systems. The outcomes are consistent with the Thailand 4.0 initiative, wherein e-business is transcending to the next level to edevelopment. Thailand 4.0 envisions transformation through creativity and innovation (Honorable Prime Minister of Thailand, 2016). This surge driven by the internet, has the potential to change relationships with customers, suppliers and intermediaries. New relationships evolve into entrepreneurship with incubator networks serving as catalysts (Carayannis and Von Zedtwitz, 2005). Novel revenue streams emerge and new business models are created. This happens when strategy blends with e-business, creating an impact that is far more than mere launching of a website.

E-business trajectory commenced with e-shop, to e-mall, to e-procurement, to e-auction. Current trends are on shared value chains (Hayes and Finnegan, 2005). The dynamics enables entrepreneurship and is transforming the rules of competition. Strategic use of e-business leads to the creation of value-drivers, viz., novelty, lock-in, complementarity, efficiency and excitement. All these parameters are interrelated, and act in unison, though in varied degrees. E-business gives rise to virtual markets where transactions face new challenges. To sustain e-business, value chain analysis should create value in virtual markets. A virtual value chain is a sequence comprising of accessing, organizing, synthesizing and distributing information. E-business thrives on strategic networks as firms, suppliers and customers complement capabilities.
\end{abstract}

Corresponding author: Salil K Sen

Email addresses for corresponding author: salilks@nida.ac.th; salil.sen@gmail.com

First submission received: 7th September 2017

Revised submission received:17th September 2017

Accepted: 21st September 2017 


\section{Introduction}

Diffusion of innovation at a reasonably accelerated rate is key to sustain entrepreneurship. This paper aims to address the linkage between the product / service offerings in the e-business domain with stages of the product / service life cycle model. Sustaining the diffusion rate is a challenges (Karakaya,Nuur and Hidalgo, 2016). With net-presence mounting super-rapidly, ebusiness is transcending to the next level to e-development. For instance, Thailand 4.0 envisions transformation through creativity and innovation (Honourable Prime Minister of Thailand,2016). However, threats such as cyber-vulnerability with ransomware, poses serious e-business resilience. This paper highlights the surge driven by the internet, as well as the need to co-create e-business resilience to cyber attacks such as wannacry. has the potential to change relationships with customers, suppliers and intermediaries (Lawerence, 2017; Seo and Park, 2017). New relationships evolve into entrepreneurship with incubator networks serving as catalysts (Carayannis and Von Zedtwitz, 2005). Novel revenue streams emerge and new business models are created. This happens when strategy blends with e-business, creating an impact that is far more than mere launching of a website.

E-business trajectory commenced with e-shop, to e-mall, to e-procurement, to e-auction. Current trends are on shared value chains (Hayes and Finnegan, 2005). The dynamics enables entrepreneurship and is transforming the rules of competition (Dandapani et. al., 2017). Strategic use of e-business leads to the creation of value-drivers, viz., novelty, lock-in, complementarity, efficiency and excitement. All these parameters are interrelated, and act in unison, though in varied degrees. Ebusiness gives rise to virtual markets where transactions face new challenges (Zott et. al., 2010). To sustain e-business, value chain analysis should create value in virtual markets. A virtual value chain is a sequence comprising of accessing, organizing, synthesizing and distributing information. Ebusiness thrives on strategic networks as firms, suppliers and customers complement capabilities.

\section{Is there a synergy to inter-relate entrepreneurial E-business with plc?}

This paper integrates the stages of the Product/Service Life Cycle onto Value streams (Marques, Cunha, Valenteand Leitão,2013). E-business models combine new business processes, technology and organization to formulate successful strategies. E-business offers enormous scope for the use of technology and e-commerce processes to develop customer relationships and enhance value. As a prelude to the PLC linked e-business model, this paper enunciates the prime value drivers of e-business. It goes on to explore the linkages that points towards an integrated theory of value creation. Entrepreneurial element emerges as the integration of e-business with Product Life Cycle (PLC) enhances the elements of the marketing mix. For instance, inter-dependencies between place and promotion could better satisfy consumers' needs. The internet based portals provide uninterrupted analysis in contrast with television commercials (Allen and Fjermestad, 2001). The ambidexterity perspective (Hu and Chen, 2016) provides pointers to the PLC centripetal momentum model. Two technological innovation performance drivers, namely, efficiency and novelty, are sort of ambidextrous, with (i) combined dimension (CD) and (ii) balance dimension (BD).

\section{Research objective: Transitioning from E-business to E-development}

\begin{tabular}{|l|l|l|}
\hline Baseline literature & $\begin{array}{l}\text { Building-on-related literature } \\
\text { references }\end{array}$ & $\begin{array}{l}\text { Gap/Scope to elucidate } \\
\text { research objectives }\end{array}$ \\
\hline $\begin{array}{l}\text { Transaction efficiency is one of } \\
\text { the prime value drivers of e- } \\
\text { business (Amit and Zott, 2001) }\end{array}$ & $\begin{array}{l}\text { Architecting gloCal (global-local), } \\
\text { real-virtual incubator networks (G- } \\
\text { RVINs) (Carayannis, E. G., \& Von } \\
\text { Zedtwitz, M. (2005) }\end{array}$ & $\begin{array}{l}\text { Scope to use centripetal } \\
\text { momentum as catalysts } \\
\text { and accelerators of } \\
\text { entrepreneurship }\end{array}$ \\
\hline $\begin{array}{l}\text { Commoditization to knowledge } \\
\text { management (Barnesa, } \\
\text { Mieczkowskab and Hintonb, }\end{array}$ & $\begin{array}{l}\text { Online shopping portal listings lack } \\
\text { comprehensiveness, omitting } \\
\text { merchandise and provide }\end{array}$ & $\begin{array}{l}\text { Entrepreneurial } \\
\text { opportunities through: } \\
\text { complementarity, lock-in, }\end{array}$ \\
\hline
\end{tabular}




\begin{tabular}{|l|l|l|}
\hline 2003) & $\begin{array}{l}\text { preferential treatment to high } \\
\text { revenue retailers (Betts, 2001) }\end{array}$ & novelty, excitement \\
\hline $\begin{array}{l}\text { The temple framework for } \\
\text { liquidity and capturing value } \\
\text { (Brunn, Jensen and Skovgaard, } \\
\text { 2002) }\end{array}$ & $\begin{array}{l}\text { Knowledge management view of e- } \\
\text { business posits that e-knowledge } \\
\text { enables and facilitates value drive } \\
\text { (Holsappleand Singh, 2000), }\end{array}$ & $\begin{array}{l}\text { The role of the qualitative } \\
\text { component within the } \\
\text { wider goals of the project }\end{array}$ \\
\hline $\begin{array}{l}\text { Establishing relationships } \\
\text { between purchasers and } \\
\text { suppliers (Coltman et. Al., 2001) }\end{array}$ & $\begin{array}{l}\text { Four faces of internet: } \\
\text { (i) business/financial models } \\
\text { (ii) relationships (iii) commerce (iv) } \\
\text { responsiveness (Damanpour, 2001) }\end{array}$ & $\begin{array}{l}\text { Charting the framework } \\
\text { matrix }\end{array}$ \\
\hline
\end{tabular}

Table 1: Transitioning from e-business to e-development: configuring the centripetal PLC model

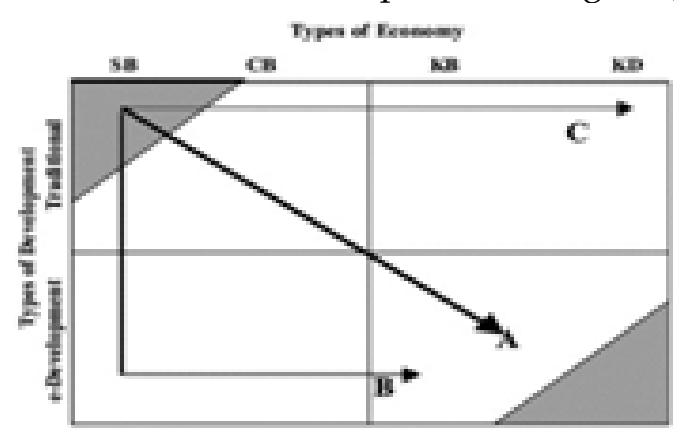

Figure i: Transitioning from e-business to e-development: configuring the centripetal PLC model

Thailand 4.0 builds substantively on connectivity-driven momentum for e-business. Figure i depicts the transition from e-business to e-development (Carayannis and Jeffrey, 2001) that creates centripetal leverage augmented-business to the next paradigm-level of e-development, that spans society and economic development.

Knowledge-driven Economy $(\mathrm{KD})$ is the frontier-rung of the e-business to e-development transition, with subsistence-based economy (SB), commodity-based economy (CB), knowledge-based economy (KB) being hierarchical steps (Papadopoulou, Andreou, Kanellis and Martakos, 2001). This proposition is illuminating this paper on the centripetal momentum engaged product/services life cycle model (Figure 1). Transaction efficiency may be achieved by reducing information asymmetries between buyers and sellers. This enables potential buyers to make speedy yet well-informed decisions (Kepler, 2002; King, Lee, and Viehland, 2004).

\subsection{Complementarity}

Complementarities are present wherever there is a bundle of goods. E-business leverages the value created, by offering bundles of complementary products and services. These complementary goods may be vertically grouped (like after sales services) or horizontally packed (like one-stopshopping). For instance, service providers on travel add-on complementary weather information, and currency exchange rate information. These peripheral services enhance the value of the core product, such as, airline tickets and vacation packages, among others (Kandampully, 2003). Complementarity could bridge online and offline businesses, popularly termed as click and mortar. This is evidenced from online browsing and ordering (evidenced as clicks), with physical delivery from out-lets (brick-and-mortar stores). Complementarity may be extended beyond core transactions (Kalakotaand Robinson, 1999). Certain service providers catalyse internet community building, through home-page building and web-page hosting. Though these services are not directly related to the core transactions. Nevertheless, they facilitate camaraderie and collaboration among members.

\subsection{Lock-in}

Successful e-businesses are those that motivate the customers to engage in repeat transactions, and creates bonds for strategic partners. Loyalty programs between book-sellers and 
credit cards enables consumers to earn bonus points from usage of card, which are redeemed with books and related accessories. Through lock-in, firms establish a relationship and motivation of trust. To fulfil individual needs of customers, e-businesses use lock-in (Joines, Scherer and Schenfele, 2003).

\subsection{Novelty}

Novelty or innovation is essential for success. Novelty thus captures 'mind share' and creates 'first mover' advantage, as evidenced in digital signatures, mobile commerce, among others (Shiralkarand Vijayaraman, 2003; Sian, Lim and Shen, 2001).

\subsection{Excitement}

Conducting innovative business via the Internet offers excitement. Finely customized communications create a profile of personal preferences. Extending from personalization to CRM, customer information is shared companywide, so that there is a better understanding about the customer at the functional level, providing a 360-degree view of the customer (Souitaris and Cohen, 2003).

\section{Methodology}

The Framework Method for the management and analysis of qualitative data dates back since 1980s. The Framework Method often termed thematic analysis or qualitative content analysis. Identifies commonalities and differences in qualitative data, before focusing on relationships. To draw descriptive and/or explanatory conclusions clustered around themes (Gale, Heath, Cameron, Rashid and Redwood, 2013). The Framework Method is deployed to elucidate the analogy between centripetal momentum with growth of clientele corresponding to the stages of the Product/Service Life Cycle.

The justification is the qualitative content in this research framework. Framework Method benefits managing and mapping the nascency, growth, maturity, sustainability phases. Multidisciplinary and mixed methods studies are becoming increasingly relevant (King,1999). It is encouraging for the author to attempt the usage of the Framework Method as the research problem of linking the scientific concept of centripetal momentum to a qualitative issue of PLC is a phenomenon under investigation. The Framework Method allows flexibility that can be adapted in this research analysis. The author concedes that, it is beyond the scope of this paper to consider in depth data collection. The emergent nature of the portals is a challenge, that is best served by the mixed methods genre of methodology, wherein the Framework Method belongs.

\subsection{Conceptual model: Momentum value drivers}

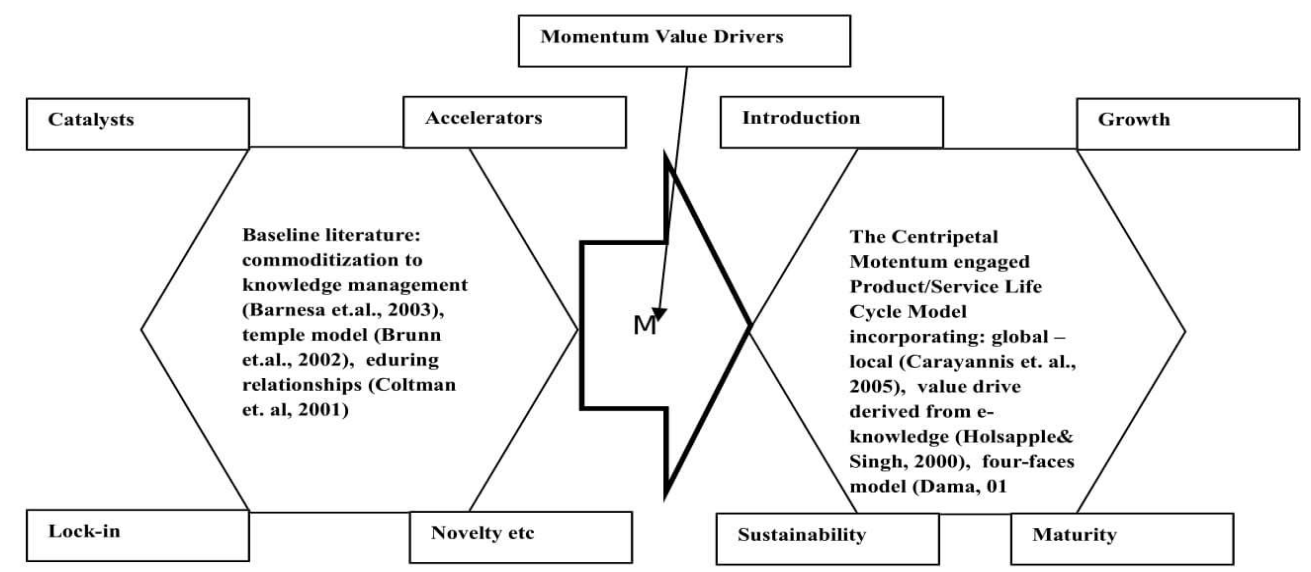

Figure 2: Literature inputs applied on to the Centripetal Momentum engaged Product/Service Life Cycle Model

The conceptual framework (Figure 2) sets the categories into two related structures (Jelassia and Leenenb, 2003), that enables analysis of the research objective stated in this paper to answer the 
research question: Transitioning from E-business to E-development. The conceptual model helps abstraction of the analogy of centripetal momentum with stages of the Product/Service Life Cycle. The baseline literature and associated building-on-related literature (Table 1) populates the left-hand part of the structure. Framework components from the baseline literature are: commoditization to knowledge management (Barnesa et.al., 2003), temple model (Brunn et.al., 2002), enduring relationships (Coltman et. al, 2001). Building-on-related literature incorporated are: Architecting gloCal (global-local), real-virtual incubator networks (G-RVINs) (Carayannis, E. G., \& Von Zedtwitz, M. (2005), preferential treatment by shopbots (Betts, 2001), knowledge management enables and facilitates value drive (Holsapple and Singh, 2000) and four faces of internet: (i) business/financial models (ii) relationships (iii) commerce (iv) responsiveness (Damanpour, 2001). They trigger transformative parameters, namely, (a) catalysts (b) accelerators (c) novelty et. al. and (d) lock-in [figure (ii)].

The right-hand segment is configured by the Centripetal Momentum engaged Product /Service Life Cycle Model (Figure 1). The Centripetal Momentum engaged Product/Service Life Cycle Model draws from the outcomes on: incorporating: global - local (Carayannis et. al., 2005), value drive derived from e-knowledge (Holsapple\& Singh, 2000). The resultant drivers being (i) introduction/nascency (ii) growth (iii) maturity and (iv) sustainability.

\subsection{Results: centripetal momentum engaged product life cycle model}

Qualitative level analysis with Framework Method was done with following steps, using the sample of online service providers (27 in number). Steps included: (a) development of analytical framework, wherein categories were formed (Figure 2). manage and organise the data. The framework enabled comparable structure configurations that on one hand, draws from literature at various temporal phases, as well as, facilitates answering the research question, on Transitioning from e-Business to e-Development. (b) explore a new analytical objective, linking centripetal momentum to PLC trajectory. This would lead to the core aspirational issue of entrepreneurship leading to the transitioning of e-business to e-development, for instance the Thailand 4.0 vision. (c) categorization and clustering leading to the process of abstraction.

(d) Configuring the Framework Method matrix (Table 2).

\begin{tabular}{|l|l|l|}
\hline Research Objective: Transitioning from e-business to e-development \\
\hline $\begin{array}{l}\text { Domentum Value } \\
\text { Drivers }\end{array}$ & Results from Framework Method & $\begin{array}{l}\text { Stages of the Centripetal } \\
\text { Momentum engaged } \\
\text { Product/Service Life Cycle } \\
\text { Model }\end{array}$ \\
\hline Catalysts & The development of themes & Introduction/Nascency \\
\hline Accelerators & Systematic search for patterns & Growth \\
\hline $\begin{array}{l}\text { Complementarity, } \\
\text { novelty, excitement }\end{array}$ & $\begin{array}{l}\text { The role of the qualitative component } \\
\text { within the wider goals of the project }\end{array}$ & Maturity \\
\hline $\begin{array}{l}\text { Lock-in for } \\
\text { Sustainability }\end{array}$ & $\begin{array}{l}\text { Four faces of internet: (i) } \\
\text { business/financial models (ii) } \\
\text { relationships (iii) commerce (iv) } \\
\text { responsiveness (Damanpour, 2001) }\end{array}$ & Sustainability or Lock-in \\
\hline
\end{tabular}

Table 2: Configuring the framework method matrix transitioning from e-business to e-development

\section{Discussion}

Novelty and lock-in have a synergistic advantage in attracting and retaining customers. Similarly, novelty and complementarity put together, are associated in a way that the main features of innovation of e-business lies in their complementary elements. Certain efficiency features of ebusinesses may be due to novel assets. It is possible to augment efficiency by reducing asymmetry of information between buyers and sellers (Lampe and Garcia, 2004). Thus, the insight emanating from 
these linkages, leads to an integrated theory of value creation (Mahadevan, 2000; Marques et. al., 2013; Michalak and Jones, 2003). In the traditional approach, each of these theories is used in isolation.

Thus, the Centripetal Momentum engaged Product Life Cycle Value Chain Framework focuses on firm's activities. In contrary to this singular approach, the sources of value creation in ebusiness emanates from an integration of business opportunities (Pant and Ravichandran, 2001). We define the business model for e-business as the content, structure and governance of transactions designed to create value through the exploitation of business opportunities (Papadopoulou et. al.,2001; Rowley, 2003). The transaction comprises of content (goods or information that are being exchanged and resources and capabilities required to enable the exchange), structure (the parties that participate in the exchange and the sequence in which the exchanges take place), and governance (ways in which flow of information, resources and goods are controlled by relevant parties) (Vassilopoulou, Ziouvelou and Pateli, 2003). Providing online information to customers can be a strategic differentiating factor. The success of e-businesses hinge on electronic linkages between supply-chain partners in terms of automated ordering, online invoicing, order-status tracking and electronic payments.

During the presales phase, information regarding the service offering is provided to customers, thereby providing a truly distinctive value proposition. The information content is rich and interactive. It informs the customers about the inventory status, delivery options, timeframe and payment conditions. Manufacturers need to leverage their brands to create online brand identity and build customer brand preference. Besides providing information, firms can collect valuable customer information regarding demographic, behavioural and psychological data. Consumers often form virtual communities to provide feedback, gather ideas and perform online comparisons. Additional services like product simulation and testing, assessing alternative financing schemes are possible online. Internet transaction mechanisms provide dynamically updated online catalogues, bundled offerings, bulletin boards and online auctions.

\section{Outcome and contribution: How super-imposing the centripetal-momentum-engaged product/service life cycle can enable transition from e-business to e-development}

\subsection{The Introductory Stage of the PLC:}

During this stage, the product or the service offering is new. The transition from brick \& mortar offering to e-business generates value in terms of better price \& enhanced service. This value stream coupled with the product/service offering cause a thrust of centripetal momentum about the customer at its core. It acts as a shield to 'lock-in' the customer. Stronger the momentum caused by the combination of the product/service offering and the value stream, the greater are the chances that the customer would stay loyal.

\subsection{The Growth Stage of the PLC:}

As the product/service offering gains momentum, it transcends to the growth stage of the PLC. By this time, the product or service offering has attracted attention of the portals who would like to add it in its list, to funnel the prospective customers towards that product or service. Added to this is the Revenue stream that emanates from increased margins. This coupled with the former duo of product \& service offering as well as the value stream, forms a dipole that imparts added momentum to the model, exerting greater influence on the customer at the centre. This additional 'lock-in' influence on the customer pushes the offering up the PLC to the accelerated growth path.

\subsection{The maturity Stage of the PLC:}

The above average growth of the product/service offering lifts it to the maturity stage of the PLC. The runaway success at the growth stage would attract competition. The customer, which is at the focus, is exposed to greater choice and is lured by competition. At this stage, more centripetal momentum is to be exerted to retain the customer. This extra force is exerted by the presence of the 
third value proposition: the market-makers, who facilitate the transaction between the buyer and seller, usually providing guarantee \& security. This is coupled by the logistical value stream.

\subsection{Sustainability or Lock-in: beyond the maturity stage}

The logistical value stream, prunes the supply chain by dis-intermediation or info-mediation, thereby cutting search costs. The triad formed by aligned force couples, viz, the product/service offering coupled with value stream, the portal coupled with revenue stream and the market-maker coupled with the logistical stream, provides superior levels of momentum to hold the customer in place.

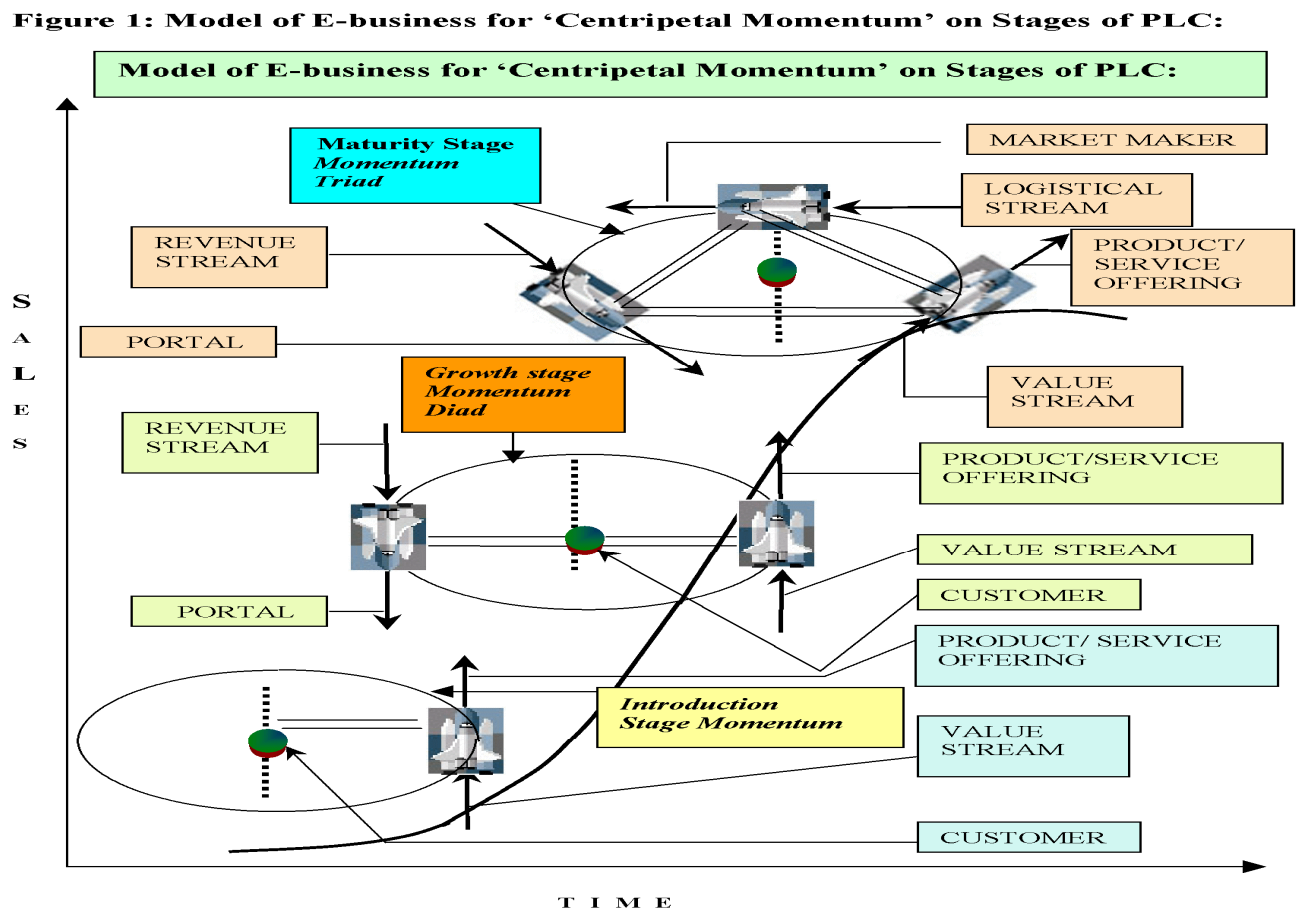

But as competition is severe, most of this momentum energy is spent to neutralize the 'pull' from competition, leaving only a fraction of the momentum to push the product/service on the PLC. This explains the flattening of growth at the maturity stage. In the event diminution of power of the triad couples, the product/offering would slide to the decline stage of the PLC.

6. Comparison and contrast of the findings of this study with respect to literature (Table 3):

\begin{tabular}{|l|l|l|}
\hline Baseline literature & $\begin{array}{l}\text { Comparing findings } \\
\text { with respect to } \\
\text { literature }\end{array}$ & $\begin{array}{l}\text { Contrasting outcomes } \\
\text { with respect to } \\
\text { literature }\end{array}$ \\
\hline $\begin{array}{l}\text { Transaction efficiency is one of the prime value } \\
\text { drivers of e-business (Amit and Zott, 2001) }\end{array}$ & Value Streams * & $\begin{array}{l}\text { Concept of centripetal } \\
\text { momentum accelerates } \\
\text { entrepreneurship }\end{array}$ \\
\hline $\begin{array}{l}\text { Architecting gloCal (global-local), real-virtual } \\
\text { incubator networks (G-RVINs) (Carayannis, E. } \\
\text { G., \& Von Zedtwitz, M. (2005) }\end{array}$ & Revenue Streams & $\begin{array}{l}\text { Entrepreneurial } \\
\text { opportunities }\end{array}$ \\
\hline $\begin{array}{l}\text { Commoditization to knowledge management } \\
\text { (Barnesa, Mieczkowskab and Hintonb, 2003) }\end{array}$ & Logistical Streams & complementarity, \\
\hline $\begin{array}{l}\text { Online shopping portal listings lack } \\
\text { comprehensiveness, omitting merchandise and } \\
\text { provide preferential treatment to high revenue } \\
\text { retailers (Betts, 2001) }\end{array}$ & Lock-in & Virtual Communities \\
\hline
\end{tabular}




\begin{tabular}{|l|l|l|}
\hline $\begin{array}{l}\text { The temple framework for liquidity and } \\
\text { capturing value (Brunn, Jensen and } \\
\text { Skovgaard, 2002) }\end{array}$ & Novelty & $\begin{array}{l}\text { Transaction Cost } \\
\text { Reduction }\end{array}$ \\
\hline $\begin{array}{l}\text { Knowledge management view of e-business } \\
\text { posits that e-knowledge enables and facilitates } \\
\text { value drive (Holsappleand Singh, 2000) }\end{array}$ & Excitement & $\begin{array}{l}\text { Information Asymmetry } \\
\text { Advantage }\end{array}$ \\
\hline $\begin{array}{l}\text { Establishing relationships between purchasers } \\
\text { and suppliers (Coltman et. Al., 2001) }\end{array}$ & $\begin{array}{l}\text { Short-term Value- } \\
\text { added Market-making } \\
\text { process }\end{array}$ & $\begin{array}{l}\text { Sustainable-term Value- } \\
\text { added Market-making } \\
\text { process }\end{array}$ \\
\hline $\begin{array}{l}\text { Four faces of internet: (i) business/financial } \\
\text { models (ii) relationships (iii) commerce (iv) } \\
\text { responsiveness (Damanpour, 2001) }\end{array}$ & $\begin{array}{l}\text { Dis-intermediation, } \\
\text { info-mediation and }\end{array}$ & Meta-mediation \\
\hline
\end{tabular}

Table 3: Comparison and contrast of findings of this study with the literature *details enumerated below

\subsection{Value Streams, Revenue Streams \& Logistical Streams:}

The blend of these three streams drives the business model for e-business. The Value stream identifies the value proposition for the buyers, sellers, the Market-makers and the Portals. The Revenue stream determines the revenue generation. The Logistical stream addresses issues related to the design of the supply chain for the e-business.

\subsection{Significance of Value Streams in E-business:}

Increased supplier base gives more options for customers, thereby giving buyers added perceived value in terms of better price, enhanced service, convenience and heightened experience. Suppliers perceive value arising out of reduced search costs, product promotion costs and lead-time. For instance, a car dealer, who spends about $\$ 25$ to close business in the brick \& mortar operation, spends zero on customer search cost for referrals from Autobytel.com. The market-maker or the portal increases the value for both buyers and suppliers, creating a virtuous cycle. More suppliers join, and the buyers get more choices. As more buyers join, suppliers get wider customer base. Simultaneously, buyers \& suppliers rely more on Market-makers/ Portals, ensuring a healthy revenue stream.

\subsection{The Four Value Streams in Sustainable E-business entrepreneurship:}

Value generated from virtual communities, dramatic reduction in transaction costs, advantage from information asymmetry and value-added market-making process, comprise the quadrangle of value streams in e-business.

\subsection{Virtual Communities:}

Communities have a distinctive focus that draws participants with common interests. For instance, WebMD is a community site that caters to medical practitioners. The members themselves generate the value derived in these communities.

\subsection{Transaction Cost Reduction:}

The e-business facilitates reduction in search costs allowing buyers, sellers, multi-firm consortiums to exchange information.

\subsection{Information Asymmetry Advantage:}

In e-business, numerous buyers are spread over large geographical areas. There are sellers with perishable products \& services (travel, hotel \& tourism). The sellers do not have perfect information on demand. Also, the buyers do not have perfect information on supply. The intermediary takes advantage of this asymmetry. Priceline.com is a business-to-consumer value stream setting up online bids and reverse auctions. 


\subsection{Value-added Market-making process:}

Security and trust are value propositions used by market-makers. In the Seafood industry, small buyers and sellers transact without knowing each other. Seafax.com provides trusted thirdparty certification to augment confidence of buyers and sellers. Similarly, eBay provides guarantees of transactions involving financial instruments ensuring privacy and reliability of delivery.

\subsection{Revenue streams in Sustainable E-business entrepreneurship:}

Revenue streams realize the value proposition in the short term. Revenue streams could emanate from increased margins (for instance Amazon.com's 50\% discount on best seller's due to dis-intermediation of the value chain generated increased margins), advertising (Yahoo, AOL)

\subsection{Logistical streams in Sustainable E-business entrepreneurship:}

Three distinct logistical streams exist in e-business, which evolve because of pruning the supply chain, viz, dis-intermediation, info-mediation and meta-mediation. By dis- intermediation, the logistical stream is shortened, as is done by Amazon.com to gain advantage over Barnes \& Noble and by Encarta over Encyclopaedia Britannica. Online journals like Emerald have found success over physical libraries by shrinking the supply chain. Info-mediation is necessitated by proliferation of information in the Net. Infomediaries are search engines \& electronic product catalogue aggregators. Meta-mediation goes beyond information dissemination and facilitates transactions. Few businessto-business segments have high vendor search costs. In such cases meta-mediation adds value to the buyers \& sellers by providing additional services.

\subsection{Specific reference to Thai retail market:}

Table 4 and Figure 2 illustrates the summary finding of the Framework Method with specific reference to Thailand 4.0. The trajectory or pathway to transition from e-business to e-development. Momentum Value Drivers were clustered on (i) catalysts, (ii) accelerators, (iii) complementarity, novelty, excitement and (iv) lock-in for sustainability. Finding were, that entities emphasized on: reforms, recognition, consumer protection, non-cash-electronic transactions and smooth dispute resolution.

\begin{tabular}{|l|l|l|}
\hline Case: Thailand 4.0: Transitioning from e-Business to e-Development \\
\hline $\begin{array}{l}\text { Momentum Value } \\
\text { Drivers }\end{array}$ & Results from Framework Method & $\begin{array}{l}\text { Stages of the Centripetal } \\
\text { Momentum engaged } \\
\text { Product/Service Life Cycle Model }\end{array}$ \\
\hline Catalyst: agriculture & $\begin{array}{l}\text { The development of themes: Online } \\
\text { agri-marts }\end{array}$ & Introduction/Nascency \\
\hline $\begin{array}{l}\text { Accelerators: Light } \\
\text { industry }\end{array}$ & $\begin{array}{l}\text { Systematic search for patterns: } \\
\text { industry segment portals }\end{array}$ & Growth \\
\hline $\begin{array}{l}\text { Complementarity, } \\
\text { Heavy industry }\end{array}$ & $\begin{array}{l}\text { Novelty, excitement: Revenue } \\
\text { streams }\end{array}$ & Maturity \\
\hline $\begin{array}{l}\text { Connectivity for } \\
\text { Sustainability: }\end{array}$ & Innovation, Smart Thailand & Sustainability or Lock-in \\
\hline
\end{tabular}

Table 4: Transitioning from e-business to e-development 


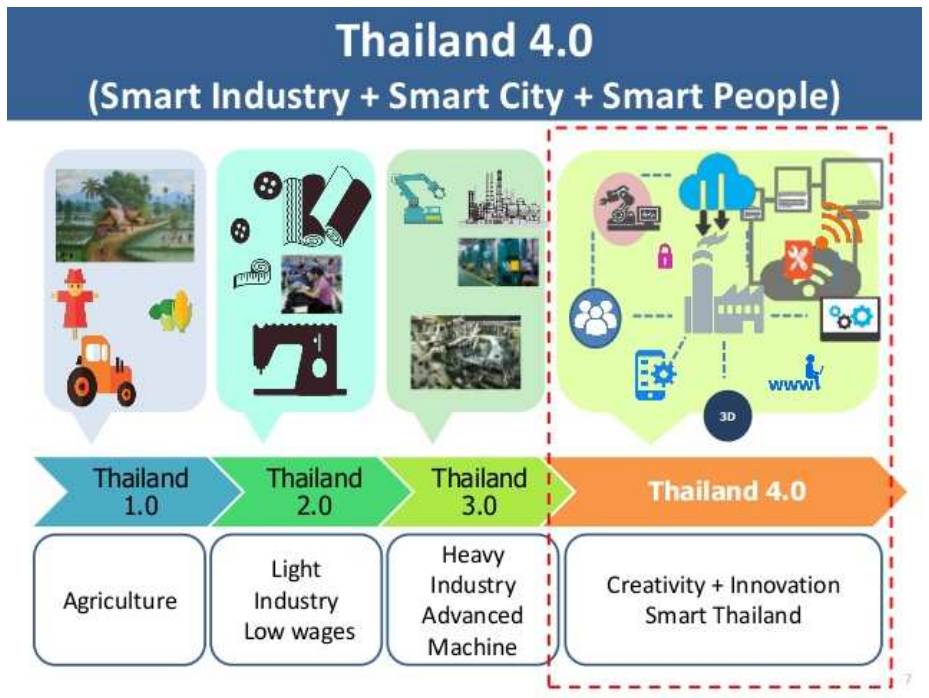

Figure 2: Transitioning from e-Business to e-Development (adapted from Languepin, 2016)

7. Discussion: 'Centripetal momentum' engaged product life cycle model for internet based ecommerce:

Marketspace in e-business can add value to elevate to a sustainable e-development system. A portal builds a community of consumers by providing information about products \& services. They are focal points to channelize traffic into websites. The market-makers are facilitators between the buyer \& the supplier (Dandapani, et.al. 2017). They possess high degree of domain knowledge. Here, the role of the portal is that of a facilitator, catalyzer and enabler. Portals funnel traffic of prospective computer software buyers to related websites.

The next level are market-makers, who leverage their domain knowledge related to software, provides implicit guarantee and security in the business transaction. For instance, auction sites serve as market-makers in the business-to-consumer segment. The Product/Service Providers are the third element in the market space, which deal directly with the customers and hence call for extensive customization. Through the interaction between these three players, viz, portals, Market-makers and product/service providers, the e-business model propagates. Prospective customers catch the attention about the products/services through the portals. The market-makers facilitate the business transaction of the product/service providers.

Author concedes some limitations. Dependence on secondary data (Rauter, Jonker, and Baumgartner, 2017) is an inadequacy for generalization. Furthermore, product - service life cycles model trajectory is assumed to be super-imposed with the centri-petal momentum concept, is a blend of social science model with physical science, needs rigorous literature review.

Since buyers cannot physically feel \& touch products on the Internet and as they are concerned regarding credit card abuse, building trust is a prime issue. Digital Signature (DS) technology is widely used to secure transactions and thereby build trust. Digital Signature (DS) technology involves encrypting messages. Two separate but interrelated 'keys' carry out this process of encryption and decryption. One party in the transaction holds the secret key (the private key) and the other party holds the public key. The Utah Digital Signature Act (1994) introduced the concept of Certifying Authority (CA). Leading CA service providers like VeriSign provides Public Key Infrastructure (PKI) based on 128-bit encryption. DS vendors develop 'keys' and encryption software like 'Smartcard Solutions' developed by RSA Securities Inc. Global sign Inc creates and manages DCs for signed and sealed e-mail messaging for secure \& confidential e-commerce \& mobile commerce applications. 


\section{Conclusion, future scope:}

Analogy of increased intensity of centrifugal momentum directed inwards at different stages of the product/service life cycle is a key assumption in this paper (diagram below).

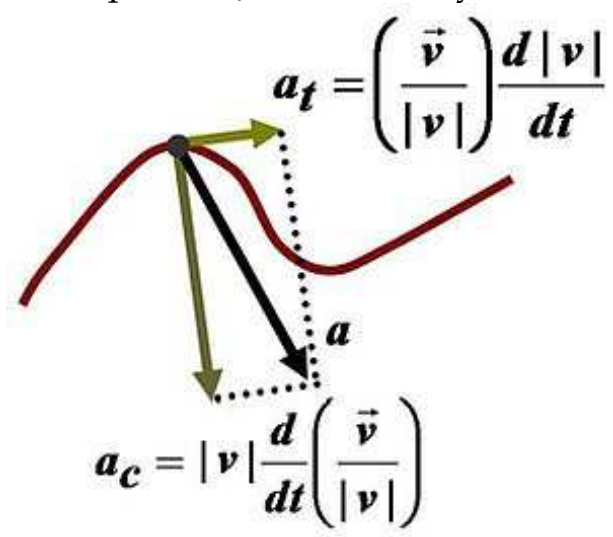

Equation of acceleration a (wikipedia definition) is a function of the second derivative. Centripetal force is created inwardly. In this case, the stages of PLC pass the nascency, growth, maturity and sustainability phases. At each stage, added a (details in Figure 1) creates higher levels of inwardly directed, customer-retainer-forces. This qualitative analogy is assumedly appropriate as the PLC is a curved trajectory.

Author admits this as a limitation, as it is not supported by PLC literature. The main objective of this paper has been to synthesize the existing value drivers of e-business and to superimpose them onto the Product Life Cycle. Secondly, the unique analogy of Centripetal Momentum exerting a compelling force on the customer (at the focus) is elucidated. In this paper, it is attempted to contribute to the value creation parameters of e-business by integrating the forces acting as Centripetal Momentum, thereby locking in the customer at the focus. The intensity of this force varies at the introduction, growth and maturity stage of the product life cycle. (Rauter, Jonker and Baumgartner, 2017).

This unique model sets the stage to analyse the strategies for e-business and to deliberate on the vital issue of security and trust. The advancement of Digital Signature technology, encryption and biometrics has led to rapid development in m-commerce, healthcare \& banking segments. The emerging trends in e-business have a lot of promise to propel it up the product life cycle curve. But future research should address the specific issues like bandwidth restrictions and legalities.

\section{References}

Allen, E. and Fjermestad, J. (2001), e-Commerce marketing strategies: an integrated framework and case analysis, Logistics Information Management, 14 1/2, 14-26.

Amit, R. and Zott, C. (2001), Value Creation in E-business, Strategic Management Journal, 22 6/7, 493-522.

Barnesa, D.; Mieczkowskab, S. and Hintonb, M. (2003), Integrating Operations and Information Strategy in e-business, European Management Journal, 21 5, 626-634.

Betts, M. (2001), Brands still matter, even for shopbots, MIT Sloan Management Review, 42 2, 9-10.

Brunn, P.; Jensen, M. and Skovgaard, J. (2002), e-Marketplaces: Crafting a Winning Strategy, European Management Journal, 20 3, 286-306.

Carayannis, E. G., \& Von Zedtwitz, M. (2005). Architecting gloCal (global-local), real-virtual incubator networks (G-RVINs) as catalysts and accelerators of entrepreneurship in transitioning and developing economies: lessons learned and best practices from current development and business incubation practices. Tec novation, 25(2), 95-110.

Carayannis, E. and Jeffrey, A. (2001) Service sector productivity: B2B electronic commerce as a strategic driver, Journal of Technology Transfer, 26 (4). 
Chan-ocha, P. (2016) Transforming Nations through Creativity and Innovation, Proceedings of the International Conference on Blue Ocean Strategy, Putrajaya International Convention Centre in Putrajaya, Malaysia.

Coltman, T.; Devinney, T.M.; Latukefu, A. and Midgley, D.F. (2001), E-business: Revolution, evolution, or hype? California Management Review, 44 1, 57-89.

Damanpour, F. (2001), E-business, E-commerce Evolution: Perspective \& Strategy, Managerial Finance,27 7, 16-33.

Dandapani, K., \& Dandapani, K. (2017). Electronic finance-recent developments. Managerial Finance, 43(5), 614-626.

Drew, S. (2003), Strategic uses of E-commerce by SMEs in the East of England, European Management Journal, 21 1, 79-88.

Gale, N.; Heath, G.; Cameron, E.; Rashid, S. and Redwood, S. (2013) Using the framework method for the analysis of qualitative data in multi-disciplinary health research; BMC Medical Research Methodology, 13:117.

Hayes, J. and Finnegan, P. (2005) Assessing the of potential of e-business models: towards a framework for assisting decision-makers, European Journal of Operational Research, Volume 160, Issue 2, pgs. 365-379.

Holsapple, C.W. and Singh, M. (2000), Toward a Unified View of Electronic Commerce, Electronic Business and Collaborative Commerce: A Knowledge Management Approach, Knowledge and Process Management,7 3, 151-164.

$\mathrm{Hu}$, B. and Chen, W. (2016) Business model ambidexterity and technological innovation performance: evidence from China, Technology Analysis and Strategic Management, Volume 28, Issue 5, pgs. 583-600.

Jelassia, T. and Leenenb, S. (2003), An E-commerce Sales Model for Manufacturing Companies: A Conceptual Framework and a European example, European Management Journal, 21 1, 38-47.

Joines, J.; Scherer, C. and Schenfele, D. (2003), Exploring motivations for consumer Web use and their implications for e-commerce, Journal of Consumer Marketing, 20 2, 90-108.

Kalakota, R. and Robinson, M. (1999), e-Business: the big challenge is business design, e-Business: Roadmap for Success, Addison-Wesley, Boston.

Kandampully, J. (2003), B2B relationships and networks in the Internet Age, Management Decision, 41 5, 443-451.

Karakaya, E.; Nuur, C and Hidalgo, A. (2016) Business model challenge: Lessons from a local solar company, Renewable Energy, Volume 85, pgs. 1026-1035.

Kepler, D. (2002), E-business: Redefining Business Process in the Chemical Industry, Dow Executive Speech of Chemical Week's Best Practices for ROI, 25 April 2002.

King, D.; Lee, J. and Viehland, D. (2004), Retailing in Electronic Commerce: Products and Services, Electronic Commerce: A Managerial Perspective, Pearson Education International, New Jersey.

King, N. (1999), The new integration imperative, Intelligent Enterprise, 214, 24-30.

Lampe, J.C. and Garcia, A. (2004), Data Mining: An in-depth look, Internal Auditing, 19 2, 4-19.

Languepin, O. (2016) Thailand 4.0, what do you need to know? Thailand Business News, www.thailand-business-news.com/economics/54286-thailand-4-0-need-know.htmlaccessed May 2017.

Lawerence, D., Townsend, F., Murphy, T., Garrie, D., Squires, J., Castelli, J., Herschmann, E., Vash, S., and Lawrence, M. (2017) It's the Cyber Crime and its Sponsors (Not My Cyber-Security), Stupid, Journal of Law and Cyber Warfare, Volume 5, Issue 2 (c), pgs. 1 - 56.

Mahadevan, B. (2000), Business Models for Internet-based E-commerce: An anatomy, California Management Review, 42 4, 55-70.

Marques, P.; Cunha, P. ; Valente, F. and Leitão; A. (2013) A Methodology for Product-service Systems Development, Procedia CIRP, Volume 7, pgs. 371 - 376. 
Merwe, R. and Bekker, J. (2003), A framework and Methodology for evaluating e-commerce Websites, Internet Research: Electronic Networking Applications and Policy, 13 5, 330-341.

Michalak, W. and Jones, K. (2003), Canadian e-commerce, International Journal of Retail \& Distribution Management, 31 1, 5-15.

Pant, S. and Ravichandran, T. (2001), A framework for information systems planning for e-business, Logistics Information Management, 14 1/2, 85-99.

Papadopoulou, P.; Andreou, A.; Kanellis, P. and Martakos, D. (2001), Trust and Relationship building in electronic commerce, Internet Research: Electronic Networking Applications and Policy,11 4, 322-332.

Papadopoulou, P.; Andreou, A.; Kanellis, P. and Martakos, D. (2001), Globalization, the Knowledge economy, and Competitiveness: A business intelligence framework for the development of SMEs, Journal of American Academy of Business, 3 1/2, 260-272.

Rauter, R., Jonker, J., \& Baumgartner, R. J. (2017). Going one's own way: drivers in developing business models for sustainability, Journal of Cleaner Production, 140, 144-154.

Rowley, J. (2003), E-business options, Strategic Direction, 19 2, 31-33.

Seo, J. H., \& Park, E. M. (2017). A Study on Financing Security for Smartphones Using Text Mining. Wireless Personal Communications, 1-19.

Shiralkar, P. and Vijayaraman, B.S. (2003), Digital Signature: Application Development Trends in EBusiness, Journal of Electronic Commerce Research, 4 3, 94-101.

Sian, K.; Lim, E.P. and Shen, Z. (2001), Mobile Commerce: Premises, Challenges, and Research agenda, Journal of Database Management, 12 3, 4-14.

Souitaris, V. and Cohen, M. (2003), Internet Ventures, Drivers of Performance, European Management Journal,21 4, 421-437.

Vassilopoulou, K.; Ziouvelou, P. and Pateli, A. (2003), Examining E-business Models: Applying a Holistic Approach in the Mobile Environment, New Paradigms in Organizations, Markets and Society. Proceedings of the 11th European Conference on Information Systems (ECIS 2003), June 16-21.

Zott, C., \& Amit, R. (2010). Business model design: an activity system perspective. Long range planning, 43(2), 216-226. 